\title{
GOVERNMENT POLICY IN THE FORMAL AND INFORMAL SECTORS*
}

\author{
JOSE MAURICIO PRADO, JR. \\ IIES/Stockholm University
}

January 19, 2007

\begin{abstract}
The aim of this paper is to quantitatively investigate the interaction between the firms' choice to operate in the formal or the informal sector and the government policy on taxation and enforcement. Informality is here defined as unregistered firms in legal activities. I develop quantitative theory, in general equilibrium, using the main determinants of informality: taxes, enforcement, regulation. I incorporate these features in a model of heterogeneous firms, where firms differ in their productivities. I use Ghironi and Melitz's (2005) industry model to show that firms with lower productivity endogeneously choose to operate in the informal sector. The model accounts quantitatively for the keys aspects in the data and allows me to back out country-specific enforcement levels. I analyze some policy reforms on taxation and enforcement and conclude that welfare gains can be fairly large. I compute the shadow value of decreasing regulation. And some counterfactual experiments are considered. Finally, I found that distortions associated to informality account for a factor of almost 2 of the output per capita difference between the richest and the poorest countries.
\end{abstract}

JEL Classification Numbers: E26,E62,H32,O17

Keywords: informal economy, productivity differences, enforcement, taxation, regulation, quantitative theory, development

${ }^{*}$ I thank my supervisor, Per Krusell, for helpful comments and suggestions, and continuous support. I am grateful for comments by Anders Fredriksson, Nicola Gennaioli, John Hassler, Martin Bech Holte, Ethan Kaplan, Emanuel Kohlscheen, Dirk Niepelt, Laudo Ogura, Stephen Parente, Torsten Persson, Kjetil Storesletten, and participants in seminars and conferences at SITE, IIES, the University of Oslo, the 2006 Villa Mondragone workshop, and the 2006 North American Summer Meeting of the Econometric Society. I am thankful to Christina Lönnblad for editorial assistance. Financial support from Jan Wallander's and Tom Hedelius' Research Foundation is gratefully acknowledged. All errors are, of course, mine. 


\section{Introduction}

The aim of this paper is to quantitatively investigate the interaction between firms' choice to operate in the informal sector and the government policy on taxation and enforcement, given a country's institutional characteristics and regulation. In short, informality is defined as unregistered businesses and/or tax avoidance. Elaborating somewhat more, Schneider and Enste (2000) define informality as "unreported income from the production of legal goods and services, either from monetary or barter transactions, hence all economic activities that would generally be taxable were they reported to the tax authorities". In recent years, the size of the informal economy has increased in Europe and the US, according to estimates by Schneider (2006). Moreover, it is also a major component of economic activities in developing economies.

The consequences of informality include, but are not limited to, the fiscal burden and the problem of having firms in the shadow of the law. Assuming the existence of a public good to be financed from tax collection, a smaller tax base implies a higher tax burden on the formal firms. The second consequence implies that firms in the informal sector have no or less access to the courts of law. Moreover, they may be infringing regulatory, labor-market and product-market obligations ${ }^{1}$. I take the view that these obligations or regulations are socially inefficient. Therefore, I consider low regulation as an indicator of a country's institutional quality. Making a parallel to what Djankov et al (2002) name the "tollbooth" view of the public choice theory of regulation, countries with better institutional quality are those where bureaucrats are less able to extract rents or bribes through inefficient regulation ${ }^{2}$.

\footnotetext{
${ }^{1}$ Farrell (2004) gives a more detailed description of these regulations.

${ }^{2}$ One can interpret the government in my model as à la Banerjee (1997), where there is a conflict of interest between the government and bureaucrats. The government maximizes household's utility at the same time that bureaucrats want to use red tape (or bad regulation).
} 
Traditionally, taxation has been blamed for the size of the informal sector. However, it cannot explain the full extent of the phenomenon of informality. An explanation should also rely on the monitoring or enforcement against firms in the informal sector, and on regulation or institutional quality ${ }^{3}$. Hernando de Soto's The Other Path (1989) is very vocal about this new strand of literature. Following de Soto's work, many papers have attempted to qualitatively explain those mechanisms involved in the determination of informal economies. However, few have quantified the effects ${ }^{4}$. In the present work, I develop quantitative theory using those main determinants of informality. In doing so, I am also able to analyze general equilibrium effects. My specific interest is in analyzing the elasticity of informality with respect to enforcement, taxation and regulation. I also draw some policy conclusions, under a public finance perspective, exploring these elasticities.

Before presenting the model, I briefly review the literature on informality. As mentioned before, the informal economy is the subject of a vast literature. A thorough review of this literature can be found in Schneider and Enste (2000) $)^{5}$. Rausch (1991), followed by Fortin, Marceau and Savard (1997), Amaral and Quintin (2006), Antunes and Cavalcanti (2006), Paula and Scheinkman (2006) and many others, analyze informal economies using the "span of control" model of Lucas (1978). In these models, agents are heterogeneous in their managerial abilities ${ }^{6}$. In a different approach, I model firms with different productivities. Since my focus in not on occupational choice, a model with firms seems more appropriate. Fortin, Marceau and Savard (1997) and Sarte (2000) model firms closely to the model in the current work. However, the first paper considers a homogeneous good (while I have differentiated ones) while Sarte (2000) considers both informal and formal

\footnotetext{
${ }^{3}$ Friedman, Johnson, Kaufmann, and Zoido-Lobaton (2000) compare different views and dismiss the taxation view.

${ }^{4}$ Antunes and Cavalcanti (2006) and Fortin, Marceau and Savard (1997) are among those few. However, they do not focus on the government policies which are studied in the present work.

${ }^{5}$ An even more recent survey of the literature can be found in Antunes and Cavalcanti (2006).

${ }^{6}$ In the case of Fortin, Marceau and Savard (1997), the agents are, in fact, firms with different managerial abilities.
} 
firms, equally dividing the production in a specific industry. In my model, a firm with productivity $z$ produces a corresponding differentiated variety $z$ and all firms with the same productivity level are in the same sector (formal or informal).

Rausch (1991) was probably the first to formally model the informal sector. However, he resorts to a minimum wage policy for large firms in order to create the informal sector. In Fortin, Marceau and Savard (1997), there is also a minimum wage. My model creates informality without resorting to minimum wage and still smaller firms endogenously choose to become informal. Azuma and Grossman (2003) provide a theoretical model of the informal sector where informality exists because firms' productive endowments are not perfectly observable. Then, the government cannot optimally extract resources from firms.

The model presented here does not focus on tax evasion per se but, of course, when a firm is in the informal sector, it is evading taxes. A huge literature has dealt with tax evasion. Allingham and Sandmo (1972) is the paper which first modelled tax evasion. Andreoni, Erard and Feldstein (1998) and Niepelt (2005) are recent contributions in the area.

I consider an economy which consists of two sectors: a formal and an informal one. The sectors are structured in monopolistic competition à la Dixit-Stiglitz, with heterogeneous firms which draw a productivity level from some given probability distribution. There are no firms with different productivities producing the same variety or different goods being produced by firms with equal productivity. The model of monopolistic competition implies that the representative household consumes all varieties. My modelling strategy closely follows the static version of the industry model of Ghironi and Melitz (2005) and Melitz (2003), which are both based on Hopenhayn (1992).

There exists a fixed regulation cost $\kappa$ in the formal sector. Alternatively, we may interpret $\kappa$ as a compliance cost or the level of lack of a country's institutional quality. Further, 
firms in the formal sector also pay a proportional tax on production at a constant rate $\tau$.

Table 1: Taxes and costs associated with economic activities

\begin{tabular}{lcc}
\hline \hline & Formal Sector & Informal Sector \\
\hline Regulation/Compliancy cost & $\kappa$ & 0 \\
Tax rate & $\tau$ & 0 \\
Enforcement rate & 0 & $e$ \\
\hline
\end{tabular}

Another choice for the firm is to operate in the informal sector. In this case, there is no fixed cost. However, there is an enforcement cost proportional to output. This cost is the result of the probability of being caught in informality and the corresponding fine (or punishment). Fortin, Marceau and Savard's (1997) interpretation of this cost is that firms engage in some costly activity to avoid being caught and pay the penalty. It is assumed that firms are better off paying the cost than risking being caught. I model this enforcement mechanism as a constant rate $e$ on the total production of informal firms.

The government relies on taxation $\tau$ upon formal businesses and the net revenue from enforcement. It spends its revenue on the public good and on the costs of enforcing informal firms. The formal sector contributes to revenue, but generates a waste in the economy, due to regulation. Enforcement reduces informality, but is costly.

In the quantitative assessment part, I back out what enforcement level is needed, country by country, to match the data for 29 countries. The model accounts, quantitatively, for the degree of informality and other key aspects, like size of government and regulation costs. The computed enforcement positively correlates with measures of tax compliance. Moreover, enforcement is positively correlated with regulation and government expenditures and, as expected, it is negatively correlated with the size of the informal sector. There is some scope for optimal government policy (using $e$ and $\tau$ as instruments). In general, most countries would do better to decrease informality, though some would benefit from increasing informality. In both cases, welfare gains can be fairly large. Countries bene- 
fiting the most are those with lower regulation costs. This suggests that a more effective policy for increasing private consumption and reducing informality is by reducing regulation costs. In special, since regulation is a distortion in the formal sector in my model, it should be zero. Then, I look at what countries would gain from decreasing regulation $(\kappa)$. I do not have a model of the determination of regulation cost, but I can compute the shadow value of decreasing regulation. Thus, we do not know how much it would cost to allow this decrease, but my model allows us to compute the benefits. Finally, I perform some counterfactual experiments by reducing the regulation cost. I conclude that a policy reducing this waste factor in the economy will have a positive impact on the provision of both private and public goods, effectively reducing the informal sector. A by-product of the model is that I can account for how the distortions associated to informality lower output per capita across countries. I found that these distortions account for a factor of 1.5 of the output per capita difference between the richest and the poorest countries.

The paper is organized as follows. The next section presents a discussion about the relationship between regulation cost and informality. Section 3 presents the model, the definition and the characterization of equilibrium as well as some comparative statics. The following section brings the calibration and the quantitative assessment of the model. The baseline calibration is solved, where the model is accounted. Section 5 consider some policy reforms. First, I analyze the reallocation of taxes and enforcement. Second, the shadow value of regulation and a counterfactual experiment is analyzed. The concluding remarks are presented in section 6 . 


\section{Regulation cost and informality}

In this section, I focus on the relationship between regulation cost and informality. The first objective is to gather data. Djankov et al (2002) present new data on the regulation of entry for 85 countries. They calculate the official costs and time legally required to begin operating a firm in these countries. I refer to them for detailed explanations of the procedures. They report both the monetary cost for fees and the time spent. The figure is measured as fraction of each country's per capita GDP. It seems that the data on per capita GDP from the World Bank's (2006) World Development Indicator dataset has suffered some revisions after it was first released. Some of the changes in the per capita GDP data were substantial: some countries had two-digit percentage point changes from the previous figures.

Since I have an interest in using the best data available to perform the quantitative assessment, I decided to recompute the total cost of regulation (fees + time) using updated World Bank data on the countries' per capita GDP in 1999 in current US\$. The new total costs and per capita GDP in 1999 figures are shown in the following table. I also include data on the size of the informal economy as a percentage of formal GDP in 1999/2000, estimated by Schneider (2006). I refer to his paper for a detailed explanation of how the size of the informal economy is estimated. In short, the informality is computed by indirect measures, like money or electricity demand and latent estimation methods using the DYMIMIC (dynamic multiple-indicators multiple-causes) model. 
Table 2: Regulation of entry, size of the informal sector, and per capita GDP in selected economies

\begin{tabular}{lccr}
\hline \hline Country name & $\begin{array}{c}\text { Regulation } \\
\text { of Entry } \\
\text { (time + cost) }\end{array}$ & $\begin{array}{c}\text { Size of the } \\
\text { Informal Sector } \\
\text { (as of formal GDP) }\end{array}$ & $\begin{array}{r}\text { Per capita } \\
\text { GDP }\end{array}$ \\
(current US\$)
\end{tabular}


continued from previous page

\begin{tabular}{lccr}
\hline \hline Country name & $\begin{array}{c}\text { Regulation } \\
\text { of Entry } \\
\text { (time + cost) }\end{array}$ & $\begin{array}{c}\text { Size of the } \\
\text { Informal Sector } \\
\text { (as o of formal GDP) }\end{array}$ & $\begin{array}{r}\text { Per capita } \\
\text { GDP } \\
\text { (current US\$) }\end{array}$ \\
\hline Japan & 0.2104 & 11.2 & 35160 \\
Jordan & 0.7164 & 19.4 & 1749 \\
Kazakhstan & 0.6847 & 43.2 & 1130 \\
Kenya & 0.6408 & 34.3 & 430 \\
Korea, Rep. & 0.2526 & 27.5 & 9554 \\
Kyrgyz Republic & 0.4238 & 39.8 & 257 \\
Latvia & 0.4381 & 39.9 & 3021 \\
Lebanon & 1.3987 & 34.1 & 5057 \\
Lithuania & 0.2306 & 30.3 & 3070 \\
Madagascar & 1.0589 & 39.6 & 236 \\
Malawi & 0.4342 & 40.3 & 158 \\
Malaysia & 0.4235 & 31.1 & 3520 \\
Mali & & 42.3 & 227 \\
Mexico & 0.7682 & 30.1 & 4982 \\
Mongolia & 0.1184 & 18.4 & 381 \\
Morocco & 0.4272 & 36.4 & 1281 \\
Mozambique & 1.7236 & 40.3 & 227 \\
Netherlands & 0.3016 & 13.1 & 25216 \\
New Zealand & 0.0169 & 12.8 & 14982 \\
Nigeria & 2.7752 & 57.9 & 303 \\
Norway & 0.1158 & 19.1 & 35448 \\
Pakistan & 0.5517 & 36.8 & 467 \\
Panama & 0.2983 & 64.1 & 3959 \\
Peru & 0.5680 & 59.9 & 2011 \\
Philippines & 0.3728 & 43.4 & 1025 \\
Poland & 0.4641 & 27.6 & 4344 \\
Portugal & 0.4768 & 22.7 & 11313 \\
Romania & 0.5348 & 34.4 & 1585 \\
Russian Federation & 0.5635 & 46.1 & 1339 \\
Senegal & 1.6100 & 45.1 & 3703 \\
Singapore & 0.2593 & 13.1 & 37097 \\
Slovak Republic & 0.4940 & 18.9 & con \\
Slovenia & 0.3804 & 27.1 & 28374 \\
South Africa & 0.1900 & 28.4 & continued on next page \\
Spain & 0.4846 & 22.7 &
\end{tabular}




\begin{tabular}{|c|c|c|c|}
\hline Country name & $\begin{array}{l}\text { Regulation } \\
\text { of Entry } \\
\text { (time }+ \text { cost) }\end{array}$ & $\begin{array}{c}\text { Size of the } \\
\text { Informal Sector } \\
\text { (as \% of formal GDP) }\end{array}$ & $\begin{array}{r}\text { Per capita } \\
\text { GDP } \\
\text { (current US\$) }\end{array}$ \\
\hline Taiwan,China & & 25.4 & \\
\hline Tanzania & 3.2862 & 58.3 & 254 \\
\hline Thailand & 0.2023 & 52.6 & 2010 \\
\hline Tunisia & 0.3284 & 38.4 & 2200 \\
\hline Turkey & 0.3781 & 32.1 & 2773 \\
\hline Uganda & 0.4980 & 43.1 & 255 \\
\hline Ukraine & 0.4231 & 52.2 & 636 \\
\hline United Kingdom & 0.0290 & 12.7 & 24879 \\
\hline United States & 0.0205 & 8.7 & 33028 \\
\hline Uruguay & 0.5491 & 51.1 & 6389 \\
\hline Venezuela, RB & 0.5108 & 33.6 & 4105 \\
\hline Vietnam & 1.7856 & 15.6 & 370 \\
\hline Zambia & 0.7643 & 48.9 & 299 \\
\hline Zimbabwe & 0.3282 & 59.4 & 478 \\
\hline
\end{tabular}

Source: Own computations using Djankov et al's (2002) and World Bank's (2006) data.

The size of the informal sector data is from Schneider (2006)

As can be noted from the table, there is a large dispersion in the three variables across the selected countries. Another point worth mentioning about these figures is that even developed economies have non-trivial sizes of the informal sector, between $8.6 \%$ and $25 \%$ of formal GDP. The correlation between per capita GDP and the size of the informal sector is -0.67. Loayza (1996) reports a similar correlation in his estimation of informality among Latin American countries. As a matter of fact, it is possible to group the countries in the table in categories relative to their level of informality, so as to observe similarities in the level of development of countries in each category. Low informality countries with an informal sector of up to $15 \%$, e.g. Switzerland, U.S. and Japan, are rich developed countries. Medium informality countries with informal sectors of between 15 and 30\%, include, for example, Italy, Spain, and Sweden. The next category groups countries with high informality (between 30 and 50\%). These countries are most of Latin America and some African and Asian countries. Finally, there are those countries with very high informality, where 


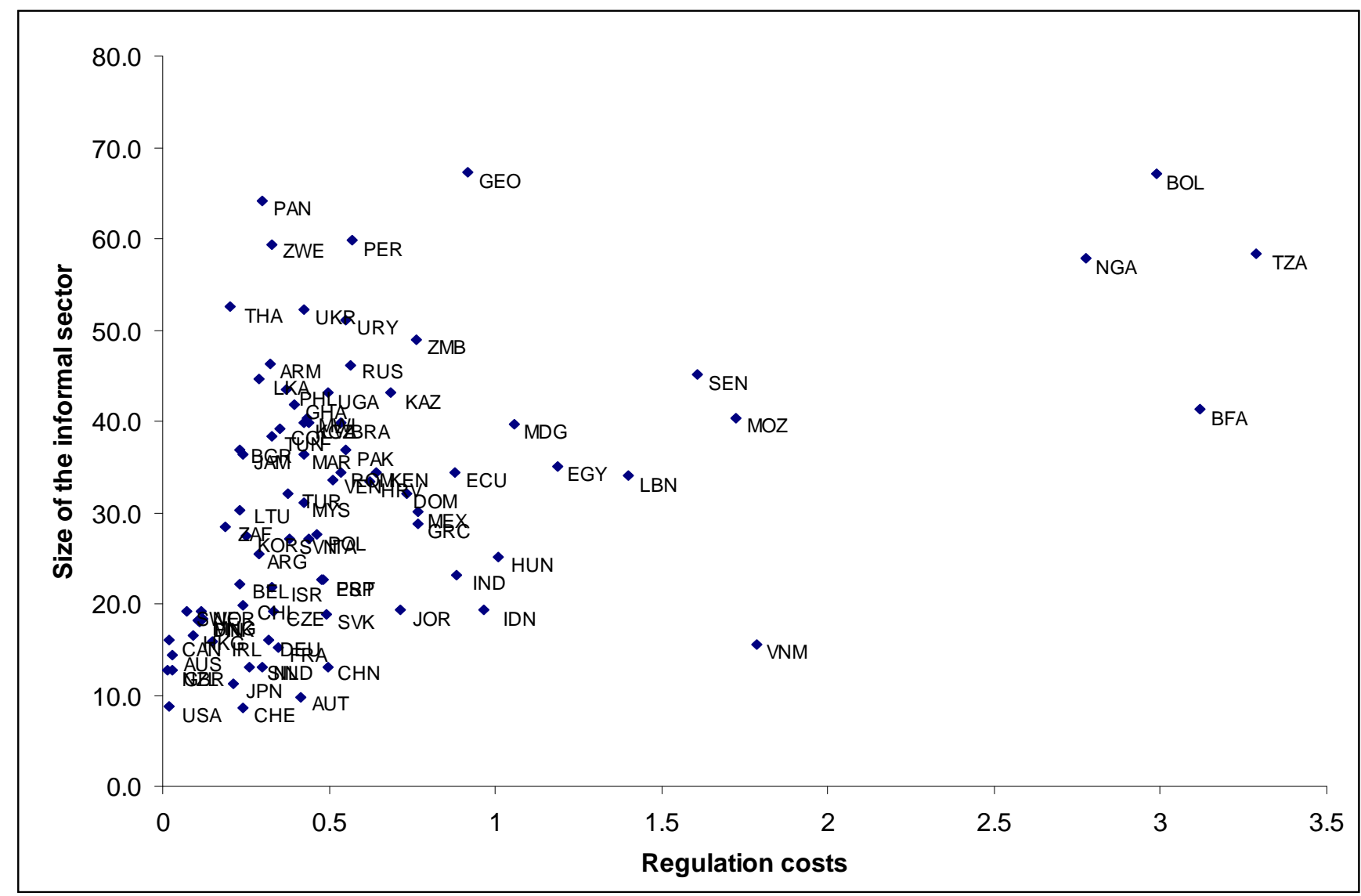

Figure 1: Regulation costs and the size of the informal sector

the informal sector is larger than the formal sector. These patological cases include very poor economies in Africa and Asia.

Another factor, not shown in the table, but reported by Schneider (2006), is the growth of the informal sector, occurring both in developing and developed economies. A further relevant point is the correlation between the size of the informal sector and the regulation cost. Figure 1 can better illustrate this point. The result is that more regulation increases the size of the informal sector. The OLS regression coefficient of this relationship is 10.13 and it is significant at the $1 \%$ level $^{7}$.

\footnotetext{
${ }^{7}$ The constant coefficient is 25.49 and is also significant at the $1 \%$ level.
} 


\section{The model}

\subsection{Basics}

Firms There is a continuum of firms of measure 1. Each firm produces a differentiated good indexed by $z \in \Omega$. Firms are heterogeneous as they produce with different technology $z$, given by a distribution probability $F(z)$ with support $\left[z_{\min }, \infty\right)$ and $z_{\min }>0$. A firm with productivity $z$ produces $\lambda z$ units of output per unit of labor, where $\lambda$ is just a parameter $(\lambda \text { can be interpreted as aggregate labor productivity })^{8}$. Productivity differences across firms then translate into differences in the unit cost of production $(w / \lambda z)$. The production function can be written as

$$
y(z)=\lambda z l(z)
$$

where $l(z)$ is the labor employed.

Firms can choose to operate in the formal or the informal sector. Producing in the formal sector requires the payment of a (fixed) regulation cost $\kappa$ (measured in terms of labor) and the payment of a proportional tax rate $\tau$ on the firm's total output $y(z)$. Firms in the informal sector pay a proportional enforcement tax $e$ on their output. The profit maximization problem of a firm with productivity $z$ is

$$
\max _{p(z)} \Pi(z) \equiv\left(1-\tau \mathcal{I}_{F}-e \mathcal{I}_{I}\right) p(z) y(z)-w l(z)-\mathcal{I}_{F} w \kappa
$$

where $\mathcal{I}_{J}$ is an indicator function that takes a value equal to 1 if the firm is operating in sector $J=F, I$ (formal or informal, respectively).

Representative Household The economy is populated by a unit mass of atomistic households. The representative household owns all firms and supplies $L$ units of labor

\footnotetext{
${ }^{8}$ To clarify, $z$ indexes both the firm's variety and its productivity. Therefore, a firm with productivity $z$ produces a corresponding variety $z$.
} 
inelastically in each period at real wage $w$. She maximizes the utility from the composite household's consumption $(C)$ and the level of public goods supplied $(G)$ :

$$
U \equiv u(C, G)
$$

where $C \equiv\left(\int_{z \in \Omega} c(z)^{(\theta-1) / \theta} d z\right)^{\theta /(\theta-1)}, \theta>1$ is the elasticity of substitution across goods and $c(z)$ is the household's consumption of good $z . G$ is a public good provided by the government. The utility function $u$ is increasing in both arguments. The budget constraint of the representative household is:

$$
C \leq w L+\Pi_{F}+\Pi_{I}
$$

the household earns labor income $w L$ and the profits in the formal $\left(\Pi_{F}\right)$ and informal sector $\left(\Pi_{I}\right)$. She spends her total income buying the composite consumption $C$.

Government The government collects taxes and enforcement penalties. Enforcement generates a revenue $E \equiv e Y_{I}$; however, there is a cost $\Psi(E)$ (with $\Psi^{\prime}(E)>0$ ) to exert this enforcement. It spends its net revenue on in the public good $G$. The government budget constraint is:

$$
G+\Psi(E) \leq \tau Y_{F}+e Y_{I}
$$

where $Y_{J}$ is total output in sector $J$.

Resource Constraint Define $Y$ as total output. Then, we can write the resource constraint of this economy:

$$
Y=Y_{F}+Y_{I}=C+G+\Psi(E)
$$

\subsection{Prices and profits}


Individual good demand Then, the individual demand for good $z$ is $y(z)$, such that

$$
y(z)=Y\left[p_{J}(z)\right]^{-\theta}
$$

where $p_{J}(z)$ is the price charged by a firm with productivity $z$ in sector $J$.

Prices All firms face a residual demand curve with constant elasticity $\theta$ in the output market, and they set flexible prices that reflect the same proportional markup $\theta /(\theta-1)$ over marginal costs given by

$$
p_{J}(z)=\frac{\theta}{(\theta-1)} \frac{1}{\left(1-\tau \mathcal{I}_{F}-e \mathcal{I}_{I}\right)} \frac{w}{\lambda z} .
$$

The above price is derived from the firms' profit maximization problem (3.2) subject to individual demand (3.7).

Given the price function (3.8), we can write a relation between the price in both sectors:

$$
p_{F}(z)=\frac{(1-e)}{(1-\tau)} p_{I}(z)
$$

Profits The profit of a firm with productivity $z$ is:

$$
\Pi_{J}(z)=\frac{\left(1-\tau \mathcal{I}_{F}-e \mathcal{I}_{I}\right)}{\theta}\left[p_{J}(z)\right]^{1-\theta} Y-\mathcal{I}_{F} w \kappa
$$

We can now study how profits change with productivity

$$
\frac{\partial \Pi_{J}}{\partial z}=\left(1-\tau \mathcal{I}_{F}-e \mathcal{I}_{I}\right) \frac{\theta-1}{\theta}\left[p_{J}(z)\right]^{1-\theta} Y z^{-1}>0 .
$$

As expected, profits are monotonically increasing in productivity, noting that, by definition, $\theta$ must be larger than 1 , and, so far as $z \geq 0$, which I assume. 
Now let us check the second derivative:

$$
\frac{\partial^{2} \Pi_{J}}{\partial z^{2}}=\left(1-\tau \mathcal{I}_{F}-e \mathcal{I}_{I}\right) \frac{(\theta-2)(\theta-1)}{\theta}\left[p_{J}(z)\right]^{1-\theta} Y z^{-2} \gtreqless 0 \text { if } \theta \gtreqless 2 .
$$

The profit function can be concave or convex in $z$, depending on the level of $\theta$, the elasticity of substitution across goods. When goods are highly complementary $(1<\theta<2)$, the function is concave with respect to $z$, whereas the profit function is convex when goods are more substitutable $(\theta>2)$.

\subsection{Definition of equilibrium}

Now that the model has been described, I proceed to define and verify the existence of the equilibrium for exogenous policy. Before, let me state some assumptions. If $\kappa=0$, the problem is trivial. There is a bang-bang solution, where all firms choose the formal (informal) sector if and only if $e>(<) \tau$. This can be seen more clearly by checking the profit expression in (3.2). Then, I assume that $\kappa>0$ :

Assumption 1 The regulation cost is positive, $\kappa>0$

The next proposition describes the conditions for equilibria in the model when policy $(e, \tau)$ is exogenous.

Proposition 1 Given Assumption 1, for e $\leq \tau$, all firms operate in the informal sector. For e $>\tau$ and a sufficiently small $z_{\min } \geq 0$, there exists a unique threshold value $z^{*} \in\left[z_{\min }, \infty\right)$ such that $\Pi_{F}\left(z^{*}\right)=\Pi_{I}\left(z^{*}\right)$, firms with $z<z^{*}$ operate in the informal sector, and firms with $z \geq z^{*}$ operate in the formal sector.

Proof: The first result of the proposition is quite trivial. If $e \leq \tau$ and $\kappa>0$, the profit function for the informal sector is always above that for the formal sector. Intuitively, if 
operating in the formal sector becomes too costly (higher proportional and fixed cost), then no firm is willing to be formal. To prove the second part of the proposition, for now assume $z_{\min }=0$. Then, we know that $\Pi_{F}(0)=-w \kappa<0$ (by Assumption 1 ) and $\Pi_{I}(0)=0$. Thus, $\Pi_{F}(0)<\Pi_{I}(0)$. To prove the existence of a single crossing, I need to show that the slope of the profit function in the formal sector is higher than the slope of the function in the informal sector. The slopes are given by the derivative $\frac{\partial \Pi_{J}}{\partial z}$. We need to show that $\frac{\partial \Pi_{F}}{\partial z}>\frac{\partial \Pi_{I}}{\partial z}:$

$$
\begin{aligned}
(1-\tau) \frac{\theta-1}{\theta}\left[p_{F}(z)\right]^{1-\theta} Y z^{-1} & >(1-e) \frac{\theta-1}{\theta}\left[p_{I}(z)\right]^{1-\theta} Y z^{-1} \\
(1-\tau)\left[p_{F}(z)\right]^{1-\theta} & >(1-e)\left[p_{I}(z)\right]^{1-\theta} \\
\frac{(1-\tau)}{(1-e)}\left[\frac{p_{I}(z)}{p_{F}(z)}\right]^{\theta-1} & >1 \\
{\left[\frac{(1-\tau)}{(1-e)}\right]^{\theta} } & >1
\end{aligned}
$$

The last inequality is true iff $e>\tau$, which we assume. Naturally, what is left is to guarantee that $z^{*} \geq z_{\min }$. We assume $z_{\min }$ to be sufficiently small, so that the unique threshold always exists. In case $z_{\min }$ is not sufficiently small, then $\Pi_{F}\left(z_{\min }\right) \geq \Pi_{I}\left(z_{\min }\right)$ and all firms will operate in the formal sector. In that case, $z^{*}=z_{\min }$ and the equilibrium is still unique. QED

The reason why we need the assumption that $e>\tau$ in the second part of the proposition is quite straightforward. If the opposite occurs, the first part of the proposition shows that no formal sector exists. The individual firm faces a decision to operate in the informal sector, paying an enforcement rate $e$, or to operate in the formal sector, where not only the tax rate is higher, but there also exists a positive fixed cost on top. Clearly, it is not worth being formal.

The following plot illustrates the single crossing property described in the Proposition. 


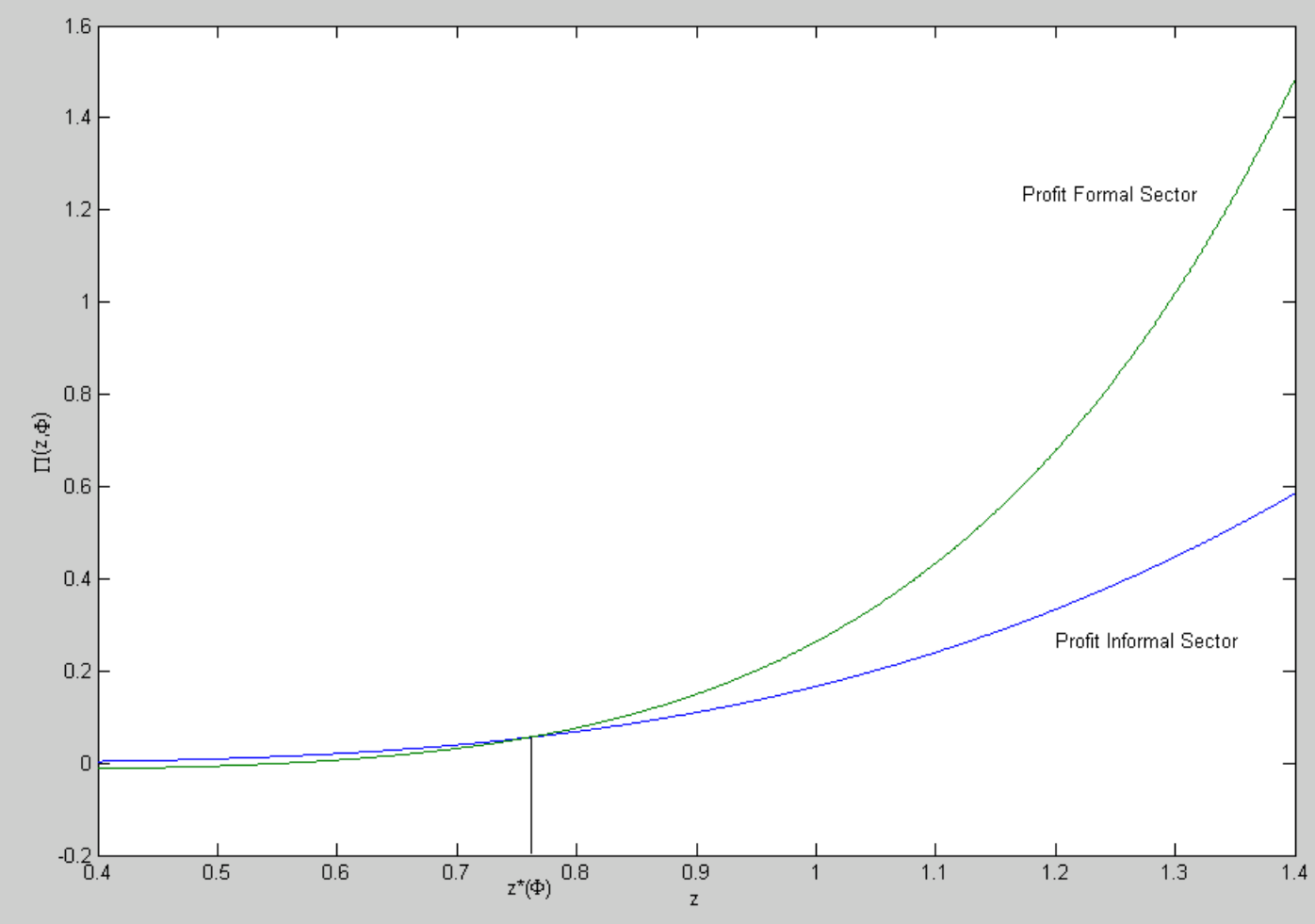

Profits in the formal and informal sectors

Now, the definition of the equilibrium follows:

Definition 1 An equilibrium with exogenous policy is a set of allocations of the good $\{y(z)\}$ and a productivity threshold $z^{\star}$ such that: (a) given exogenous government policy $(\tau, e)$ and wages $w$, firms maximize profit; (b) given prices $(w, p(z))$ and exogenous government policy $(\tau, e, G)$, the representative household maximizes composite consumption $C$; (c) the budget constraint of the government holds with equality; (e) markets (for both labor and goods) clear; and, finally, ( $f$ ) firms with productivity $z<z^{*}$ operate in the informal sector and firms with $z \geq z^{*}$ operate in the formal sector. 


\subsection{Parametrization of the productivity distribution}

I parametrize the distribution of productivities following Ghironi and Melitz (2005). They assume the distribution to be Pareto with the lower bound $z_{\min }$ and the shape parameter $k>\theta-1$. The parameter $k$ indexes the dispersion of productivity. The standard deviation of $\log$ productivity is equal to $1 / k$. And the condition that $k>\theta-1$ ensures that the variance in firm size is finite. The distribution of productivity which is Pareto also induces the distribution of size of firms to be Pareto. Ghironi and Melitz (2005) claim that this distribution fits firm-level data for the U.S. quite well. The cumulative distribution function is $F(z)=1-\left(z_{\min } / z\right)^{k}$ and the probability distribution function is given by

$$
f(z)=k z_{\min }^{k} z^{-k-1} .
$$

Considering the threshold equilibrium described in Proposition 2, we can compute the share of firms in the formal sector using the CDF:

$$
1-F\left(z^{*}\right)=\left(z_{\min } / z^{*}\right)^{k},
$$

and since there is a measure one of firms, the number of firms in the formal sector, $N_{F}$, equals $\left(z_{\min } / z^{*}\right)^{k}$.

\subsection{Determination of equilibrium}

This section shows the analytical solution of the equilibrium considering the parametrization of the productivity distribution given in the previous subsection. It is enough to solve for only three endogenous variables to determine the equilibrium, namely, the threshold of productivity $z^{*}$, the wage $w$, and total output $Y$. For that, we need three equilibrium 
conditions.

The first equilibrium condition is the cutoff condition $\Pi_{F}\left(z^{*}\right)-\Pi_{I}\left(z^{*}\right)=0$, where the two profit functions cross. Applying the parametrization, the condition becomes

$$
\frac{(1-\tau)}{\theta}\left[p_{F}\left(z^{*}\right)\right]^{1-\theta} Y-w \kappa=\frac{(1-e)}{\theta}\left[p_{I}\left(z^{*}\right)\right]^{1-\theta} Y .
$$

After some algebra has been done and using equation (3.9), we get the following expression:

$$
\Phi_{1}\left(z^{*} ; \tau, e, \kappa, \theta, \lambda\right) \equiv\left[\left(\frac{1-\tau}{1-e}\right)^{\theta}-1\right]\left[\frac{\theta}{(\theta-1)} \frac{1}{(1-e) \lambda}\right]^{1-\theta} \frac{z^{* \theta-1}}{\theta \kappa}=\frac{w^{\theta}}{Y}
$$

We can express the left-hand side as a function $\Phi_{1}$ of the threshold $z^{*}$. The right-hand side is a simple function of the other two endogenous variables: $w$ and $Y$. Remember that, for now, I consider $\tau$ and $e$ as exogenous policy variables. They will be endogenized as the problem of the government is made more explicit in section 5. Moreover, so far, the equilibrium condition refer to the optimal choices of firms, which take these policies as given.

Another equilibrium condition to consider is the labor-market clearing, which is given by

$$
\int_{z_{\min }}^{\infty} \frac{y(z)}{\lambda z} d F(z)+\kappa\left(1-F\left(z^{*}\right)\right)=L
$$

This condition can also be rewritten, in a similar fashion to (3.17), as follows:

$$
\begin{gathered}
\Phi_{2}\left(z^{*} ; \tau, e, \kappa, \theta, \lambda\right) \equiv \\
\frac{k z_{\min }^{k}}{\left[L-\kappa\left(z_{\min } / z^{*}\right)^{k}\right] \lambda^{1-\theta}}\left(\frac{\theta}{(\theta-1)}\right)^{-\theta}\left((1-e)^{\theta} \int_{z_{\min }}^{z^{*}} z^{\theta-k-2} d z+(1-\tau)^{\theta} \int_{z^{*}}^{\infty} z^{\theta-k-2} d z\right)=\frac{w^{\theta}}{Y} \\
\text { where } \int_{z_{\min }}^{z^{*}} z^{\theta-k-2} d z=\frac{z^{* \theta-k-1}-z_{\min }^{\theta-k-1}}{\theta-1-k} \text { and } \int_{z^{*}}^{\infty} z^{\theta-k-2} d z=\frac{-z^{* \theta-k-1}}{\theta-1-k} \text {. The left-hand side }
\end{gathered}
$$


is expressed as a function $\Phi_{2}$ of the threshold $z^{*}$ and other exogenous variables. And the right-hand side as a function of $w$ and $Y$.

Now, notice that the two equations (3.17) and (3.19) have the same right-hand side. Then, equating them, we get the equilibrium threshold $z^{*}$ as a function of only exogenous variables:

$$
\begin{gathered}
\frac{k z_{\min }^{k}}{\left(L-\kappa\left(z_{\min } / z^{*}\right)^{k}\right)}\left((1-e)^{\theta} \int_{z_{\min }}^{z^{*}} z^{\theta-k-2} d z+(1-\tau)^{\theta} \int_{z^{*}}^{\infty} z^{\theta-k-2} d z\right)= \\
\left(\frac{(1-\tau)^{\theta}-(1-e)^{\theta}}{1-e}\right) \frac{z^{* \theta-1}}{(\theta-1) \kappa} .
\end{gathered}
$$

Finally, we need a third equilibrium condition and this is given by the goods' market clearing. The aggregate of all individual outputs equals total output in the economy:

$$
Y=\left(\int_{z_{\min }}^{\infty} y(z)^{(\theta-1) / \theta} d F(z)\right)^{\theta /(\theta-1)}
$$

This condition yields the following expression of wage as a function of the threshold $z^{*}$ :

$$
w^{\theta-1}=k z_{\min }^{k}\left(\frac{(\theta-1) \lambda}{\theta}\right)^{\theta-1}\left\{(1-e)^{\theta-1} \frac{z^{* \theta-k-1}-z_{\min }^{\theta-k-1}}{\theta-1-k}-(1-\tau)^{\theta-1} \frac{z^{* \theta-k-1}}{\theta-1-k}\right\}
$$

Given $z^{*}$ (by equation 3.20), we can compute $w$ using the above expression. And given $z^{*}$ and $w$, we can compute $Y$, using either equations (3.17) or (3.19).

\subsection{Comparative Statics}

The equilibrium conditions allow us to do some comparative statics with respect to the fundamentals of the model. I summarize the results in the following subsubsections. 


\subsubsection{Tax rate $\tau$}

An increase in the tax rate makes it more costly to operate in the formal sector. At the margin, firms will find it profitable to switch to the informal sector, which leads to an increase in $z^{*}$.The increase in taxes has two effects in the same direction, reducing wages. The first effect is the direct effect of taxes, reducing demand for labor across sectors; the second effect is the moving of workers from formal firms to informal ones. Since informal firms have lower productivity, the marginal productivity of labor is reduced, as is the wage. For total output, the increase in taxes has three effects: (1) the direct effect of the higher tax rate, increasing $Y$ thanks to less resources being wasted in the regulation cost $\kappa$; (2) the increase in $z^{*}$, reducing output; (3) the decrease in wages further reduces output. The net effect on total output is therefore ambiguous. In most of the cases I studied, the first effect is larger than the sum of the last two; thus a higher $Y$ as the tax rate rises.

\subsubsection{Enforcement rate $e$}

Compared to the tax increase, raising the enforcement rate generates an opposite effect. A higher $e$ makes it more costly to operate in the informal sector, which makes firms on the margin switch to the formal sector, thereby decreasing $z^{*}$. Once more, there are two effects on wages. While the first effect, which reduces demand for labor, remains, the second effect is inverted, moving workers from informal to formal firms. The latter effect increases wages, since marginal productivity of labor is higher (formal firms have higher productivity). This second effect is high for countries with low regulation costs ${ }^{9}$. If the first effect is higher, $w(e)$ will be decreasing everywhere. If the first effect is higher for low levels of enforcement and lower after some threshold $\bar{e}$, then wages become U-shaped. As before, there are three separate effects on total output. Analyzing the separate effects on

\footnotetext{
${ }^{9}$ In the model, $\kappa$ works as a softener of the effects on productivity and it directly affects the formal firms, which are the more productive ones. Analytically, $w_{e \kappa}<0$.
} 
output as $e$ increases: (1) the direct effect reduces $Y$, because of the distortionary effect of $\kappa ;(2)$ a decrease in $z^{*}$ increases output; and (3) an ambiguious effect on wages. If wages are decreased, output drops. Instead, if wages increase, output also rises. In most of the cases studied, the net effect on output is negative.

\subsubsection{Regulation $\operatorname{cost} \kappa$}

An increase in regulation works in the same line as an increase in taxes. The threshold $z^{*}$ increases and wages go down. Once more, the effect on output is ambiguous.

\subsubsection{Elasticity of substitution across goods $\theta$}

The increase in $\theta$ can be translated as an increase in competition, since the elasticity of substitution determines the firms' markup over costs. Since there is a fixed cost in the formal sector, formal firms on the margin between being formal or informal are hurt proportionally more than the informal firms on the same margin. Then, the marginal formal firms switch to the informal sector, thus increasing $z^{*}$. The increase in $\theta$ also means that demand for goods becomes more elastic and demand increases strongly for goods with lower prices (i.e., for goods with higher productivity). This shifts labor to high productivity firms which explains why there is an increase in wages. Finally, the increase in wages raises total output.

\subsubsection{Labor supply $L$}

An increase in $L$ makes all firms hire more, but more jobs are proportionally created in the formal (high productivity) sector, thereby increasing wages. More workers imply more production. And, in fact, total output increases linearly with $L$. Informal firms on the margin switch to the formal sector, reducing $z^{*}$. 


\subsubsection{Total factor productivity $\lambda$}

In this model, the parameter $\lambda$, which represents total factor productivity in the economy, only works as a scale parameter. The production function is $y(z)=\lambda z l(z)$ and total output can be written as:

$$
Y=\lambda\left(\int z l(z)^{(\theta-1) / \theta} d F(z)\right)^{\theta /(\theta-1)} .
$$

Then, it increases total production and since it augments labor productivity, there is an increase in wages. Since it is just a scale parameter, no effect in the threshold $z^{*}$ is observed.

\subsubsection{Lower bound for productivity $z_{\min }$}

An increase in the minimum productivity level shifts the distribution of firm productivity to the right. Clearly, marginal productivity of labor is higher and wages increase. The effect on output is also positive. As $z_{\min }$ increases, the threshold $z^{*}$ also increases. However, the size of the informal sector as a percentage of formal output remains constant.

\subsubsection{Shape parameter $k$}

Parameter $k$ indexes the dispersion of productivity draws: dispersion decreases as $k$ increases, and the firm productivity levels are increasingly concentrated toward their lower bound, $z_{\min }$. By definition, an increase in $k$ decreases the marginal productivity of labor and wages go down. Since firms will be more concentrated towards $z_{\min }$, the threshold $z^{*}$ is reduced. The reduction in wage implies that total output will also be lower. 


\section{Quantitative assessment}

So far, we have studied the mechanisms qualitatively involved in the model. In this section, I calibrate the model to 29 countries and make some quantitative experiments. The countries chosen are the OECD countries plus Brazil. The reason for using OECD countries is that the data on total government revenue is more uniform and available and the firms' characteristics are more similar when I calibrate for the distribution of productivities. Nonetheless, the cross-section of countries is quite diverse, including both developed and emerging economies.

\subsection{Solving the model}

The model is solved as follows. This is the implementation of the equilibrium described in subsection 3.5 .

1. Given $\left(z_{\min }, \theta, k, L, \tau, e, \kappa\right), z^{*}$ is computed. The TFP $\lambda$ does not affect $z^{*}$.

2. Then, wage $w$ and total output $Y$ are calculated using equations (3.22) and either (3.17) or (3.19). Here, $\lambda$ is just a level parameter and does not affect the results.

3. The size of the informal sector $(I N F)$ is the ratio of informal sector output $Y_{I}$ and total output in the formal sector $Y_{F}$.

$$
I N F=\frac{Y_{I}}{Y_{F}}=\left(\frac{1-e}{1-\tau}\right)^{\theta-1} \frac{z_{\min }^{\theta-k-1}-z^{* \theta-k-1}}{z^{* \theta-k-1}}
$$

where

$$
Y_{F}=Y * k z_{\min }^{k}\left[\frac{\theta}{(\theta-1)} \frac{w}{(1-\tau) \lambda}\right]^{1-\theta} \frac{z^{* \theta-k-1}}{k+1-\theta}
$$

and

$$
Y_{I}=Y * k z_{\min }^{k}\left[\frac{\theta}{(\theta-1)} \frac{w}{(1-e) \lambda}\right]^{1-\theta} \frac{z^{* \theta-k-1}-z_{\min }^{\theta-k-1}}{\theta-1-k}
$$


4. Per capita GDP is formal sector output $Y_{F}$ divided by $L$.

5. The amount of labor employed in each sector is computed, respecting the clearing condition $L_{F}+L_{I}+\kappa\left(z_{\min } / z^{*}\right)^{k} \equiv L$, where $\left(z_{\min } / z^{*}\right)^{k}$ is the proportion of formal firms in the economy.

6. Then, I calculate government expenditures as a percentage of formal GDP ( $g \equiv$ $\left.G / Y_{F}\right)$.

\subsection{Choosing the parameters}

The parameters that need to be calibrated are: (1) productivity distribution parameters: $z_{\min }, k$; (2) elasticity of substitution across goods, $\theta$; (3) regulation cost, $\kappa$; and (4) labor supply, $L$. The model also has two policy variables: $\tau$ and $e$, the tax and enforcement rates, respectively.

The model period is the average life time of firms. Since this is a static model, it makes sense to consider a large time frame (about ten years). Following what Ghironi and Melitz (2005) did, I will use the value of $\theta$ from Bernard et al (2003). They set $\theta=3.8$, which is calibrated to fit U.S. plant data. They report that the standard deviation of log U.S. plant sales is 1.67. This standard deviation in the model is equal to $1 /(k-\theta+1)$. The choice of $\theta$ implies that $k=3.4$ (which satisfies the requirement that $k>\theta-1$ ). Across all computations, I normalize the size of the work force $L$ to 1 and the lowest value of productivity $z_{\min }$ is also set to 1 . Also, the scale parameter $\lambda$ (the "TFP") is set to 1 on the baseline calibration ${ }^{10}$. The cost of enforcement for the government is set equal to the revenue from enforcement, $\Psi(E)=E$, so that the government only benefits from taxation upon formal firms.

\footnotetext{
${ }^{10}$ It will be calibrated to different values for each country when analyzing output per capita differences among countries.
} 
1. I match government expenditures, regulation cost and the size of the informal sector by choosing $\tau, e, \kappa$. The data on government expenditures for OECD countries is the total government revenue from OECD (2003). The data on Brazil's total government revenue comes from the Central Bank of Brazil. The data on the size of the informal sector is from Schneider (2006) and the data on regulation cost is from Djankov et al (2002) and my own calculations (described in Section 2). However, the calculated regulation cost is not exactly $\kappa$. It is the monetary cost (of fees and time) as a percentage of formal per capita GDP. Then, the relation between $\kappa$ and the reported regulation cost is:

$$
\kappa=\frac{Y_{F}}{L} * \frac{\text { regulation cost }}{w} .
$$

This implies that the model is solved with a system of six non-linear equations to determine seven variables: $z^{*}, Y, w, \tau, e, \kappa$. The six equations are: 3.17 (or 3.19), 3.20, 4.23, $4.25,4.26, g=G / Y_{F}$.

\subsection{Baseline results}

The following table brings the results for the baseline calibration. The data used in the calibration is found in the three first columns: government expenditures as a percentage of formal GDP, the size of the informal economy as a percentage of formal GDP and the regulation cost. The next three columns bring the results for tax and the fixed cost on formal businesses and the enforcement rate on informal business for the 29 countries in the sample. The table is sorted by the enforcement rate. Countries with lower enforcement rates are at the top of the table. 
Table 3: Benchmark computation

\begin{tabular}{|c|c|c|c|c|c|c|}
\hline \multirow[b]{2}{*}{ Countryname } & \multicolumn{3}{|c|}{ Data } & \multicolumn{3}{|c|}{ Model } \\
\hline & $G / Y_{F}$ & Informal $/ Y_{F}$ & Regulation cost & $\tau$ & $\kappa$ & $e$ \\
\hline United States & 28.9 & 8.7 & 0.0205 & 0.289 & 0.0355 & 0.3369 \\
\hline Australia & 30.8 & 14.3 & 0.0292 & 0.308 & 0.0495 & 0.3553 \\
\hline Korea & 23.6 & 27.5 & 0.2526 & 0.236 & 0.3509 & 0.3677 \\
\hline New Zealand & 33.9 & 12.8 & 0.0169 & 0.339 & 0.0305 & 0.3688 \\
\hline Mexico & 17.3 & 30.1 & 0.7682 & 0.173 & 0.9748 & 0.3803 \\
\hline Canada & 35.9 & 16.0 & 0.0211 & 0.359 & 0.0382 & 0.3891 \\
\hline United Kingdom & 36.1 & 12.7 & 0.0290 & 0.361 & 0.0538 & 0.4081 \\
\hline Brazil & 31.7 & 39.8 & 0.5362 & 0.317 & 0.7681 & 0.4344 \\
\hline Turkey & 31.3 & 32.1 & 0.3781 & 0.313 & 0.5648 & 0.4376 \\
\hline Ireland & 31.0 & 15.9 & 0.1515 & 0.310 & 0.2497 & 0.4513 \\
\hline Japan & 26.4 & 11.2 & 0.2104 & 0.264 & 0.3322 & 0.4803 \\
\hline Norway & 40.4 & 19.1 & 0.1158 & 0.404 & 0.2161 & 0.4953 \\
\hline Poland & 35.0 & 27.6 & 0.4641 & 0.350 & 0.7503 & 0.4958 \\
\hline Portugal & 34.0 & 22.7 & 0.4768 & 0.340 & 0.7806 & 0.5122 \\
\hline Spain & 35.0 & 22.7 & 0.4846 & 0.350 & 0.8046 & 0.5206 \\
\hline Greece & 37.0 & 28.7 & 0.7692 & 0.370 & 1.2702 & 0.5335 \\
\hline Slovak Rep & 34.4 & 18.9 & 0.4940 & 0.344 & 0.8285 & 0.5384 \\
\hline Switzerland & 29.8 & 8.6 & 0.2422 & 0.298 & 0.4011 & 0.5442 \\
\hline Czech Rep & 38.9 & 19.1 & 0.3324 & 0.389 & 0.5974 & 0.5460 \\
\hline Finland & 47.0 & 18.1 & 0.1071 & 0.470 & 0.2250 & 0.5508 \\
\hline Germany & 37.7 & 16.0 & 0.3203 & 0.377 & 0.5738 & 0.5532 \\
\hline Italy & 43.3 & 27.1 & 0.4407 & 0.433 & 0.8122 & 0.5595 \\
\hline Belgium & 45.3 & 22.2 & 0.2316 & 0.453 & 0.4562 & 0.5612 \\
\hline Hungary & 39.1 & 25.1 & 1.0068 & 0.391 & 1.7445 & 0.5773 \\
\hline Sweden & 52.3 & 19.2 & 0.0746 & 0.523 & 0.1733 & 0.5773 \\
\hline Denmark & 51.5 & 18.0 & 0.1104 & 0.515 & 0.2522 & 0.5907 \\
\hline Netherlands & 41.2 & 13.1 & 0.3016 & 0.412 & 0.5764 & 0.5940 \\
\hline France & 45.7 & 15.2 & 0.3472 & 0.457 & 0.7059 & 0.6197 \\
\hline Austria & 44.0 & 9.8 & 0.4140 & 0.440 & 0.8253 & 0.6578 \\
\hline
\end{tabular}

Source: Data: Djankov et al (2002), OECD(2003), Schneider (2006); Model: own computations

This baseline computation provides two results. The first is that I can match key facts of the data for each country. The second result is the computed enforcement rates. In this computation, enforcement is a residual. It is important, therefore, to check whether the figures I get is really measuring tax enforcement. In lieu of better data, I constructed two measures of tax compliance using data on staffing of government audit offices in OECD 
countries (OECD, 2004). One measure is the ratio of total audit staff and total population. The second is the same ratio, but just considering the labor force in the denominator. Enforcement is strongly positively correlated to these two measures. The correlations are 0.58 and 0.59 , respectively ${ }^{11}$. The following figure illustrates the relation between enforcement and total audit personnel per capita.

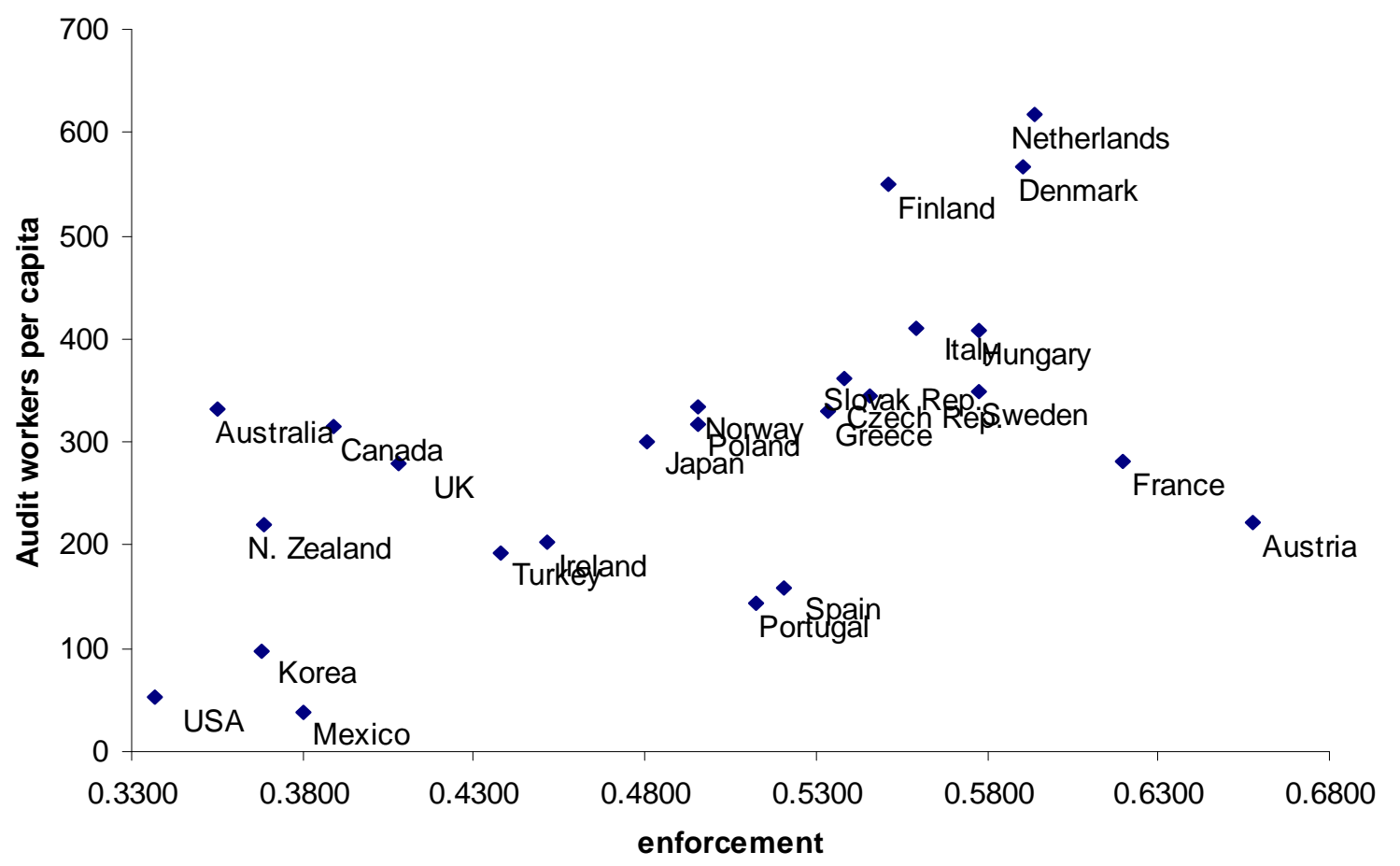

Enforcement and total audit workers per capita

The computed enforcement allows us to better understand its relationship to the other variables in the model, namely, regulation, the tax rate and the size of the informal sector. Take the case of Switzerland and the United States with similar levels of informality. The U.S. have the smallest enforcement rate in the sample while Switzerland has a large one. The difference between these two countries is that the U.S. have much smaller regulation

\footnotetext{
${ }^{11}$ Both correlation coefficients are significant at $1 \%$.
} 
costs than Switzerland. The same can be said of Austria as compared to the United States. Austria has the largest enforcement rate in the sample and a small level of informality, like the U.S. and Switzerland. But since Austria has such high regulation costs (in the order of 20 times more), it needs to enforce the informal sector to a considerably larger extent. Otherwise, it does not create enough incentives to make firms switch to the formal sector. At the other side of the spectrum, consider countries with a large informal sector, like Brazil, Mexico and Turkey. These countries have low enforcement, as would be expected. Another point about why these countries can exert low enforcement is that taxation is not so high, especially in the case of Mexico. Greece has the same level of informality and the same amount of regulation cost as Mexico. However, they present very different enforcement levels. This is driven by the fact that Greece has more than twice the level of government expenditures than Mexico.

Next, table 5 presents some OLS estimations using the computed enforcement as a dependent variable. In column (1), we see that there is a positive correlation between the regulation fixed cost $(\kappa)$ and enforcement. However, the effect is weak since other factors that are also relevant for endogenously determining the enforcement rate are omitted. The next columns present the effect of regulation on enforcement controlling for these other factors, namely the size of government $\left(G / Y_{F}\right)$ and the size of the informality $\left(Y_{I} / Y_{F}\right)$. In columns (2) to (4), the correlation of regulation and enforcement becomes very significant. Moreover, less enforcement is linked to more informality, as would be expected. Moreover, a larger size of government is associated with more enforcement. The results remain the same, even when replacing $\kappa$ by the regulation measure used as input in the computations or when using the tax rate $\tau$ instead of the size of government. 
Table 4: Relation of enforcement and regulation, informality, and government size

\begin{tabular}{lcccc}
\hline \hline & $(1)$ & $(2)$ & $(3)$ & $(4)$ \\
\hline Regulation & $0.097^{* *}$ & $0.101^{* * *}$ & $0.148^{* * *}$ & $0.135^{* * *}$ \\
& $(0.038)$ & $(0.022)$ & $(0.041)$ & $(0.022)$ \\
Size of government & & $0.008^{* * *}$ & & $0.008^{* * *}$ \\
& & $(0.001)$ & & $(0.001)$ \\
Informality & & & $-0.005^{* *}$ & $-0.004^{* * *}$ \\
& & & $(0.002)$ & $(0.001)$ \\
constant & $0.446^{* * *}$ & $0.145^{* * *}$ & $0.521^{* * *}$ & $0.215^{* * *}$ \\
& $(0.025)$ & $(0.042)$ & $(0.039)$ & $(0.044)$
\end{tabular}

$\begin{array}{lllll}\text { Adj. R-squared } & 0.17 & 0.73 & 0.29 & 0.79\end{array}$

Notes: Standard errors in parenthesis: ${ }^{*}$ significant at $10 \%$;

${ }^{* *}$ significant at $5 \% ;{ }^{* * *}$ significant at $1 \%$

\section{Policy reforms}

\subsection{Realocatting taxes and enforcement}

After considering the baseline case, a natural question is whether the government is choosing tax and enforcement in the best possible way. I take the level of government expenditures and the regulation cost, from the previous section, as given and maximize household utility choosing the tax and enforcement rates. The problem of the government is:

$$
\max _{\tau, e} u(C, \bar{G}),
$$

where $\bar{G}$ is the level of public good given by the baseline calibration.

Since $u_{C}>0$, the choice here is basically the pair $\left(\tau^{*}, e^{*}\right)$ which delivers the largest possible $C$. The following table gives the results for the optimal policy. The first four columns bring the $\tau, e$, and the size of the informal sector, which were computed in the baseline calibration. The next two columns present the optimal policy. The following column presents the percentage gain of consumption with the optimal policy, while the 
last column brings the size of informality after the policy.

Table 5: Optimal policy on taxes and enforcement

\begin{tabular}{|c|c|c|c|c|c|c|c|}
\hline \multirow[b]{2}{*}{ Countryname } & \multicolumn{3}{|c|}{ Benchmark } & \multicolumn{4}{|c|}{ Optimal policy } \\
\hline & $\tau$ & $e$ & $Y_{I} / Y_{F}$ & $\tau^{*}$ & $e^{*}$ & $\Delta C(\%)$ & $Y_{I} / Y_{F}$ \\
\hline United States & 0.289 & 0.3369 & 8.7 & 0.2699 & 0.3552 & 1.69 & 0.0 \\
\hline Australia & 0.308 & 0.3553 & 14.3 & 0.2784 & 0.3924 & 2.23 & 0.5 \\
\hline Korea & 0.236 & 0.3677 & 27.5 & 0.2408 & 0.3591 & 0.06 & 30.9 \\
\hline New Zealand & 0.339 & 0.3688 & 12.8 & 0.3055 & 0.3710 & 3.90 & 0.0 \\
\hline Mexico & 0.173 & 0.3803 & 30.1 & 0.2041 & 0.3103 & 2.00 & 61.4 \\
\hline Canada & 0.359 & 0.3891 & 16.0 & 0.3169 & 0.3975 & 4.77 & 0.0 \\
\hline United Kingdom & 0.361 & 0.4081 & 12.7 & 0.3310 & 0.4388 & 2.54 & 0.4 \\
\hline Brazil & 0.317 & 0.4344 & 39.8 & 0.3068 & 0.4445 & 0.14 & 33.9 \\
\hline Turkey & 0.313 & 0.4376 & 32.1 & 0.3086 & 0.4432 & 0.04 & 29.5 \\
\hline Ireland & 0.310 & 0.4513 & 15.9 & 0.3145 & 0.4408 & 0.07 & 18.5 \\
\hline Japan & 0.264 & 0.4803 & 11.2 & 0.2828 & 0.4094 & 1.52 & 24.8 \\
\hline Norway & 0.404 & 0.4953 & 19.1 & 0.3915 & 0.5112 & 0.46 & 13.4 \\
\hline Poland & 0.350 & 0.4958 & 27.6 & 0.3521 & 0.4929 & 0.01 & 28.8 \\
\hline Portugal & 0.340 & 0.5122 & 22.7 & 0.3509 & 0.4923 & 0.31 & 29.3 \\
\hline Spain & 0.350 & 0.5206 & 22.7 & 0.3603 & 0.5022 & 0.28 & 28.9 \\
\hline Greece & 0.370 & 0.5335 & 28.7 & 0.3764 & 0.5247 & 0.09 & 32.4 \\
\hline Slovak Rep & 0.344 & 0.5384 & 18.9 & 0.3603 & 0.5025 & 0.85 & 29.2 \\
\hline Switzerland & 0.298 & 0.5442 & 8.6 & 0.3187 & 0.4504 & 2.65 & 24.1 \\
\hline Czech Rep & 0.389 & 0.5460 & 19.1 & 0.3965 & 0.5322 & 0.17 & 23.3 \\
\hline Finland & 0.470 & 0.5508 & 18.1 & 0.4556 & 0.5653 & 0.74 & 12.1 \\
\hline Germany & 0.377 & 0.5532 & 16.0 & 0.3892 & 0.5249 & 0.61 & 23.3 \\
\hline Italy & 0.433 & 0.5595 & 27.1 & 0.4279 & 0.5652 & 0.06 & 24.5 \\
\hline Belgium & 0.453 & 0.5612 & 22.2 & 0.4454 & 0.5700 & 0.18 & 18.6 \\
\hline Hungary & 0.391 & 0.5773 & 25.1 & 0.4043 & 0.5564 & 2.66 & 33.2 \\
\hline Sweden & 0.523 & 0.5773 & 19.2 & 0.4948 & 0.5911 & 0.48 & 9.0 \\
\hline Denmark & 0.515 & 0.5907 & 18.0 & 0.5007 & 0.6028 & 0.84 & 12.2 \\
\hline Netherlands & 0.412 & 0.5940 & 13.1 & 0.4256 & 0.5574 & 1.10 & 21.5 \\
\hline France & 0.457 & 0.6197 & 15.2 & 0.4678 & 0.5963 & 0.70 & 21.6 \\
\hline Austria & 0.440 & 0.6578 & 9.8 & 0.4571 & 0.5903 & 3.54 & 23.3 \\
\hline
\end{tabular}

Comparing the enforcement to the baseline, 13 countries out of 29 increased the enforcement rate. From these, 9 are the countries with lowest regulation costs in the sample. The average gain in consumption is $1.2 \%$. Canada and Austria had the largest increases in $C$. Canada benefits from a large decrease in taxes whereas Austria benefits from a decrease in enforcement, generating an increase in the informal sector. In the Canadian case, 
the country had low informality and low regulation. Then, a small increase in enforcement is enough to reduce further informality and allow for tax cuts in the formal sector. In the case of Austria, it had the largest enforcement rate and quite low informality. The optimal policy was to increase informality and avoid wasting resources with regulation. The economy with regulation made it possible to substantially boost private consumption, keeping the government revenue constant by increasing taxes in the formal sector by 1.7 percentage points.

The countries with lowest regulation are also the countries that manage to reduce their informal sectors substantially more. In particular, U.S., New Zealand, and Canada managed to eliminate the informal sector with the optimal policy. What happens here is that the elasticity of informality with respect to tax and enforcement is pretty large and larger for countries with lower regulation. About the other countries, most of them will end up with sizes of the informal sector between 20 and 33\%, except Mexico which gets an increase to $61 \%$. The optimal policy for Mexico is to decrease the tax base in the formal sector and increase taxes, remembering that Mexico had very low taxes. This allows Mexico to raise the same government revenue. Why is this policy optimal? Because enforcement is reduced in the informal sector, which is now $60 \%$ of the formal economy. This reduction in enforcement increases profits in the informal sector, which directly benefits the representative household's consumption.

As concerns the optimal choice of enforcement, one could ask what makes the U.S. want such a low e and Denmark, for example, a much higher one? The answer about the difference between U.S. and Denmark lies in the size of government. Remember that $e$ must be larger than $\tau$, otherwise no formal sector exists and the supply of public good is zero. Then, Denmark starts with a "lower bound" for enforcement that is much higher than that of the U.S. Due to the high Danish level of government expenditures in comparison to the U.S., Denmark needs a tax rate almost twice the American one. Why is this 
optimal? Denmark manages to keep a not so large informal sector (18\% in the baseline calibration; and $12 \%$ using the optimal policy), having a large government and five times larger regulation. The U.S. starts off with much better conditions: 40\% smaller government size and low regulation.

The fact that many countries are close to their optima and most of the countries with high regulation still keep significant levels of informality suggests that the regulation costs play a large role in determining the level of the informal sector. If these countries reduce the regulation costs, it will allow them to substantially reduce the informal sector. This is exactly what is observed for the countries with lowest regulation in the sample.

\subsection{Reforming regulation}

\subsubsection{Shadow value of regulation}

As seen in the previous section, regulation plays a important role in determining the size of the informal sector. But it is not scope for government policy in this model. Nonetheless, the model can be useful in measuring the benefit of reducing regulation. Then, the natural question to ask is what is the shadow value of regulation costs $(\kappa)$ in the equilibrium I have computed. The next table presents the percentage consumption increase for three different changes in regulation: (1) a reduction of $1 \%$ in $\kappa ;(2)$ a reduction of $10 \%$ in $\kappa$; and (3) a reduction of $\kappa$ by 0.01 .

Table 6: Consumption $\%$ increase for different changes in $\kappa$

\begin{tabular}{lccc}
\hline \hline Countryname & $-1 \%$ & $-10 \%$ & -0.01 \\
\hline United States & 0.05 & 0.50 & 1.42 \\
New Zealand & 0.04 & 0.45 & 1.48 \\
Canada & 0.06 & 0.58 & 1.52 \\
United Kingdom & 0.08 & 0.84 & 1.57 \\
\hline \multicolumn{4}{c}{ continued on next page }
\end{tabular}




\begin{tabular}{lccc}
\multicolumn{4}{l}{ continued from } \\
Countryname & $-1 \%$ & $-10 \%$ & -0.01 \\
\hline Australia & 0.07 & 0.72 & 1.45 \\
Sweden & 0.14 & 1.43 & 0.81 \\
Finland & 0.12 & 1.25 & 0.54 \\
Denmark & 0.14 & 1.45 & 0.56 \\
Norway & 0.10 & 1.03 & 0.46 \\
Ireland & 0.08 & 0.81 & 0.31 \\
Japan & 0.07 & 0.73 & 0.21 \\
Belgium & 0.11 & 1.20 & 0.25 \\
Switzerland & 0.08 & 0.82 & 0.19 \\
Korea & 0.06 & 0.62 & 0.17 \\
Netherlands & 0.10 & 1.13 & 0.18 \\
Germany & 0.09 & 1.01 & 0.16 \\
Czech Rep & 0.10 & 1.05 & 0.17 \\
France & 0.13 & 1.28 & 0.17 \\
Turkey & 0.04 & 0.79 & 0.12 \\
Austria & 0.12 & 1.23 & 0.14 \\
Italy & 0.11 & 1.13 & 0.14 \\
Brazil & 0.07 & 0.81 & 0.11 \\
Poland & 0.08 & 0.89 & 0.11 \\
Portugal & 0.09 & 0.90 & 0.11 \\
Spain & 0.09 & 0.93 & 0.11 \\
Slovak Rep & 0.07 & 0.92 & 0.11 \\
Greece & 0.09 & 0.96 & 0.07 \\
Mexico & 0.04 & 0.52 & 0.04 \\
Hungary & 0.12 & 1.07 & 0.06 \\
\hline
\end{tabular}

It is clear that reducing regulation makes informality smaller. It becomes "cheaper" to operate in the formal sector. However, production in the formal sector is also taxed. Then, the results for the first two columns (the percentage decreases in $\kappa$ ) show that countries with higher taxation benefit more from the reduction in regulation. Take the case of Mexico, with low taxation, which is the country that benefits the least from the policy. Meanwhile, Sweden and Denmark are the countries which benefit the most. Not by coincidence, they have the largest size of government. The third column shows results for a decrease of 0.01 in the regulation cost. This time, the countries to benefit more were exactly the countries with lower regulation which is not surprising, since these are the 
countries with the largest percentage decrease in regulation.

\subsubsection{A counterfactual experiment}

The purpose of this counterfactual experiment is to explore the shadow value of regulation. What reduction in the regulation $\cos t \kappa$ is needed to achieve the level of informality of Switzerland, $8.6 \% ?^{12}$ The following table presents the answer to this question.

Table 7: Reduction in $\kappa$ to achieve Swiss informality

\begin{tabular}{lccc}
\hline \hline Countryname & $\kappa^{\prime}$ & $\Delta \kappa$ & $\Delta C(\%)$ \\
\hline Switzerland & 0.4011 & 0.0 & 0.0 \\
United States & 0.0353 & -0.6 & 0.0 \\
New Zealand & 0.0248 & -18.7 & 0.1 \\
United Kingdom & 0.0432 & -19.7 & 0.2 \\
Canada & 0.0267 & -30.1 & 0.2 \\
Australia & 0.0367 & -25.9 & 0.3 \\
Sweden & 0.0926 & -46.6 & 0.7 \\
Austria & 0.6813 & -17.4 & 0.8 \\
Japan & 0.2477 & -25.4 & 1.0 \\
Denmark & 0.1330 & -47.3 & 1.1 \\
Finland & 0.1188 & -47.2 & 1.1 \\
Norway & 0.1071 & -50.4 & 1.2 \\
Ireland & 0.1387 & -44.5 & 1.4 \\
Netherlands & 0.3410 & -40.8 & 1.8 \\
Belgium & 0.1638 & -64.1 & 2.2 \\
France & 0.3404 & -51.8 & 2.3 \\
Germany & 0.2663 & -53.6 & 2.4 \\
Korea & 0.0986 & -71.9 & 2.5 \\
Czech Rep & 0.2254 & -62.3 & 2.7 \\
Turkey & 0.1169 & -79.3 & 3.2 \\
Italy & 0.1899 & -76.6 & 3.4 \\
Slovak Rep & 0.2800 & -66.2 & 3.5 \\
Brazil & 0.1096 & -85.7 & 3.6 \\
Poland & 0.1688 & -77.5 & 3.6 \\
Portugal & 0.2159 & -72.3 & 3.7 \\
\hline \multicolumn{4}{r}{ continued on next page } \\
rynn
\end{tabular}

\footnotetext{
${ }^{12}$ Switzerland was chosen because it has the lowest size of the informal sector in the sample of 29 countries.
} 


\begin{tabular}{lccc}
\multicolumn{4}{l}{ continued from previous page } \\
Countryname & $\kappa^{\prime}$ & $\Delta \kappa$ & $\Delta C(\%)$ \\
\hline Spain & 0.2212 & -72.5 & 3.7 \\
Greece & 0.2231 & -82.4 & 4.8 \\
Mexico & 0.1626 & -83.3 & 5.0 \\
Hungary & 0.3216 & -81.6 & 5.4 \\
\hline
\end{tabular}

Once more, the countries benefitting the most are those with large regulation. The average unweighted increase in consumption is $2.1 \%$. It is important to mention that this experiment is done keeping the level of government expenditures of the baseline calibration and holding taxes and enforcement constant.

\section{Accounting for income differences}

One interesting question that can be answered with the baseline model is how much of the distortions associated with informality can account for the income differences among the richest and the poorest countries. Since $\lambda$ works in the model as a level parameter, I set it equal to 1 for all countries and the equilibrium results will not change. The level of formal output $Y_{F}$, however, only captures the income differences due to regulation, enforcement, and taxation associated with the matched size of the informal economy for each country. The computed output strongly correlates with measures of actual per capita GDP as can be observed in the following plot.

Let now the model total-factor productivity $\lambda$ be calibrated so that the per capita GDP in the model equals the value $\mathrm{n}$ the data. The calibrated $\lambda$ is also strongly correlated with measures of TFP in the data. Here I use the one computed by Hall and Jones (1999). The correlation is 0.7 and is significant at $1 \%$ level. 


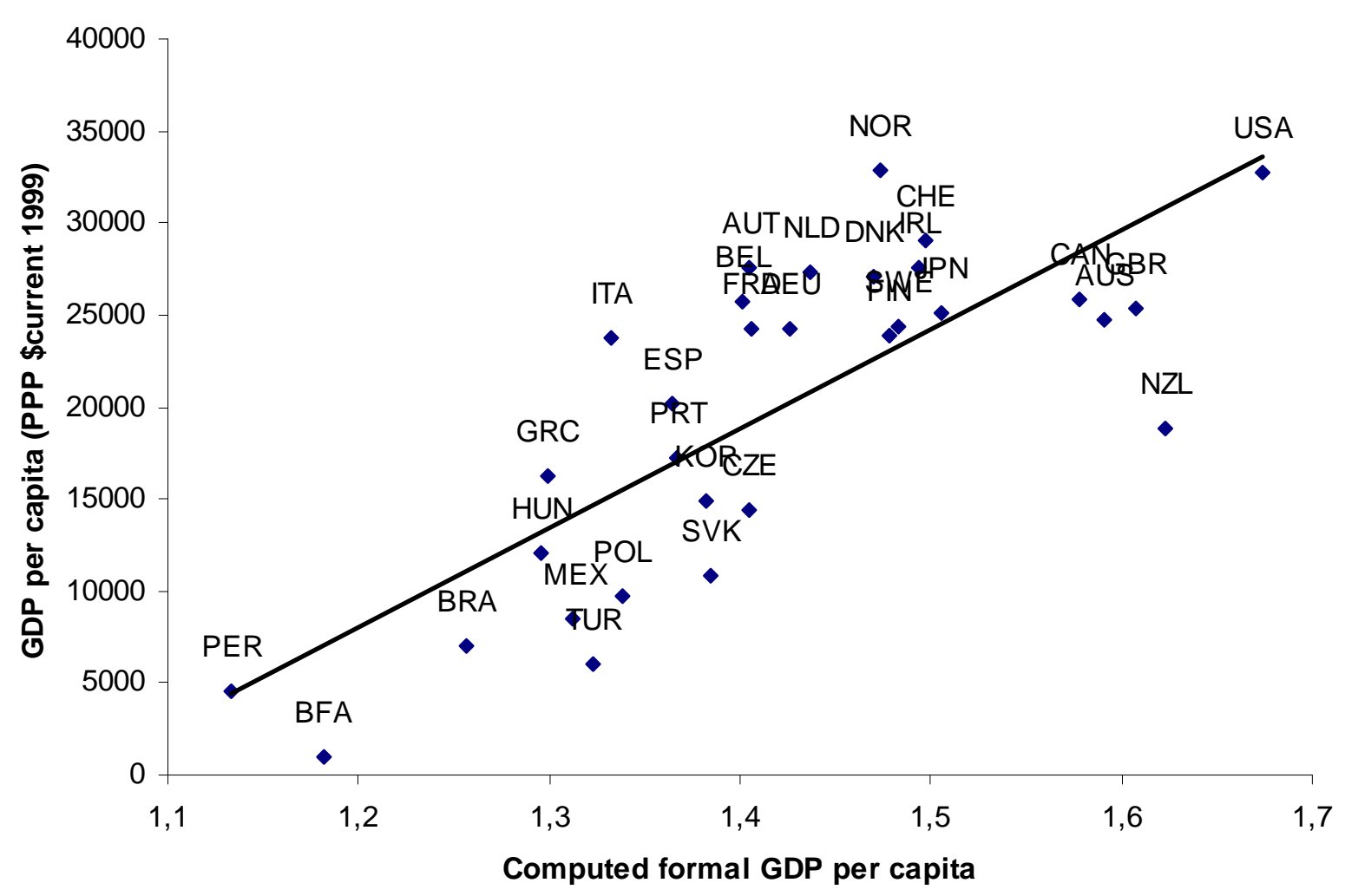

The next table brings figures for: (1) actual GDP per capita (PPP, measured in current US\$) in 1999; (2) the same figure relative to the U.S level; (3) the computed output per capita $\left(Y_{F}\right)$ with $\lambda=1$; (4) the ratio between $Y_{F}$ and $Y_{F}^{U S A}$, the U.S. formal output per capita; (5) the TFP $\lambda$; and (6) the Hall and Jones's (1999) TFP $A$ relative to the U.S. Not surprisingly, the U.S. formal GDP is much higher than that of Burkina Faso. Hall and Jones (1999) reports that the richest countries in the world have an output per worker that is roughly 35 times that of the poorest countries. And this is about the difference between U.S.'s and Burkina Faso's GDP per capita in the data shown below. Following Hall and Jones (1999), we can break down the differences in the actual output into differences associated with savings, human capital, and total factor productivity. The last item is a remainder and can be thought to capture differences in "social infrastructure", a term used by Hall and Jones (1999). They argue that savings rates account for a factor 
of 1.5 and human capital acconts for a factor of 3. We observe that $Y_{F}^{U S A}$ is higher by a factor of 1.5 in our model. It is not huge, but is nontrivial. Building on Hall and Jones (1999), I conclude that regulation, enforcement, and taxation of formal activities leading to a large informal sector accounts for roughly a factor of 1.5 of the output differences. TFP differences account for the remaining factor of 5 , so that $1.5 \times 3 \times 1.5 \times 5 \approx 35$.

Table 8: Income and TFP across countries

\begin{tabular}{lrcrrrr}
\hline \hline Country & GDP per capita & GDPpc/GDPpc & \multicolumn{1}{c}{$Y_{F}$} & $Y_{F} / Y_{F}^{U S A}$ & $\lambda$ & TFP \\
\hline United States & 32732 & 1.00 & 1.674 & 1.00 & 19556 & 1.000 \\
New Zealand & 18843 & 0.58 & 1.623 & 0.97 & 11608 & 0.631 \\
Canada & 25811 & 0.79 & 1.577 & 0.94 & 16364 & 1.034 \\
United Kingdom & 25399 & 0.78 & 1.608 & 0.96 & 15796 & 1.011 \\
Australia & 24699 & 0.75 & 1.591 & 0.95 & 15520 & 0.856 \\
Sweden & 24377 & 0.74 & 1.483 & 0.89 & 16438 & 0.897 \\
Finland & 23900 & 0.73 & 1.478 & 0.88 & 16170 & 0.728 \\
Denmark & 27120 & 0.83 & 1.469 & 0.88 & 18457 & 0.705 \\
Norway & 32854 & 1.00 & 1.474 & 0.88 & 22289 & 0.699 \\
Ireland & 27556 & 0.84 & 1.494 & 0.89 & 18448 & 0.709 \\
Japan & 25105 & 0.77 & 1.506 & 0.90 & 16673 & 0.658 \\
Belgium & 25743 & 0.79 & 1.401 & 0.84 & 18374 & 0.978 \\
Switzerland & 28991 & 0.89 & 1.498 & 0.89 & 19359 & 0.883 \\
Korea. Rep. & 14849 & 0.45 & 1.382 & 0.83 & 10745 & 0.580 \\
Netherlands & 27332 & 0.84 & 1.437 & 0.86 & 19021 & 0.946 \\
Germany & 24231 & 0.74 & 1.427 & 0.85 & 16985 & 0.912 \\
Czech Republic & 14442 & 0.44 & 1.405 & 0.84 & 10277 & 0.241 \\
France & 24241 & 0.74 & 1.405 & 0.84 & 17248 & 1.126 \\
Turkey & 6018 & 0.18 & 1.323 & 0.79 & 4547 & 0.503 \\
Austria & 27534 & 0.84 & 1.405 & 0.84 & 19594 & 0.979 \\
Italy & 23721 & 0.72 & 1.333 & 0.80 & 17797 & 1.207 \\
Brazil & 6985 & 0.21 & 1.256 & 0.75 & 5561 & 0.758 \\
Poland & 9726 & 0.30 & 1.338 & 0.80 & 7267 & 0.235 \\
Portugal & 17221 & 0.53 & 1.367 & 0.82 & 12595 & 0.755 \\
Spain & 20187 & 0.62 & 1.365 & 0.82 & 14791 & 1.107 \\
Slovak Republic & 10800 & 0.33 & 1.384 & 0.83 & 7801 & 0.241 \\
Greece & 16269 & 0.50 & 1.299 & 0.78 & 12524 & 0.674 \\
\hline & & & & continued on next page
\end{tabular}




\begin{tabular}{lrccrrr}
$\begin{array}{l}\text { continued from previous page } \\
\text { Country }\end{array}$ & GDP per capita & GDPpc/GDPpc USA & $Y_{F}$ & $Y_{F} / Y_{F}^{U S A}$ & $\lambda$ & TFP \\
\hline Mexico & 8433 & 0.26 & 1.313 & 0.78 & 6424 & 0.926 \\
Hungary & 12017 & 0.37 & 1.296 & 0.77 & 9276 & 0.293 \\
Peru & 4561 & 0.14 & 1.133 & 0.68 & 4025 & 0.409 \\
Burkina Faso & 990 & 0.03 & 1.182 & 0.71 & 837 & 0.101 \\
\hline
\end{tabular}

\section{Concluding Remarks}

I construct a simple general-equilibrium micro-founded model to account, quantitatively, for the degree of informality across countries. In the model, firms choose which sector to belong to based on proportional taxation in the formal sector, "regulation" of formal firms (fixed, red-tape cost $\kappa$ ), and enforcement of/punishment against informality. Large enough firms find formality beneficial. Using the model, I back out what enforcement level is needed, country by country, to match the data for 29 countries. The model accounts, quantitatively, for the degree of informality and other key aspects, like size of government, regulation costs, and income differences. The computed enforcement positively correlates with indirect measures of tax compliance. Moreover, enforcement is positively correlated with regulation and government expenditures and, as expected, it is negatively correlated with the size of the informal sector. There is some scope for policy reform (using $e$ and $\tau$ as instruments). In general, most countries would do better to decrease informality, though some would benefit from increasing informality. In both cases, welfare gains can be fairly large. Countries benefiting the most are those with lower regulation costs.

The previous result suggests that a more effective policy for increasing private consumption and reducing informality is by reducing regulation costs. In special, since regulation is a distortion in the formal sector in my model, it should be zero. Then, I look at what countries would gain from decreasing regulation $(\kappa)$, in a hypothetical exercise. I do not have a model of determination of regulation cost, but I can compute the shadow value of decreasing regulation. Thus, we do not know how much it would cost to allow 
this decrease, but my model allows us to compute the benefits. Finally, I perform some counterfactual experiments by reducing the regulation cost. I conclude that a policy reducing this waste factor in the economy will have a positive impact on the provision of both private and public goods, effectively reducing the informal sector.

A by-product of the model is that I can account for how the distortions associated to informality lower output per capita across countries. I found that these distortions account for a factor of 1.5 of the output per capita difference between the richest and the poorest countries.

\section{References}

[1] Allingham, Michael and Agnar Sandmo (1972): "Income tax evasion: A theoretical. analysis," Journal of Public Economics 1, 323-338.

[2] Amaral, Pedro S. and Erwan Quintin (2006): "A Competitive Model of the Informal Sector", Journal of Monetary Economics, 53, 1541-1553.

[3] Andreoni, James, Brian Erard, and Jonathan Feinstein (1998): "Tax Compliance", Journal of Economic Literature, 36, 818-860.

[4] Antunes, Antonio R. and Tiago V. de V. Cavalcanti (2006): "Start Up Costs, Limited Enforcement, and the Hidden Economy", European Economic Review, forthcoming.

[5] Azuma, Yoshiaki and Herschel I. Grossman (2003): "A Theory of the Informal Sector", mimeo.

[6] Banerjee, Abhijit V. (1997): "A Theory of Misgovernance," The Quarterly Journal of Economics, 112, 1289-1332. 
[7] Bernard, Andrew B., Jonathan Eaton, J. Bradford Jensen, and Samuel Kortum (2003): "Plants and Productivity in International Trade," American Economic Review, 93,12681290.

[8] De Soto, Hernando (1989) The Other Path: the Invisible Revolution in the Third World, Harper and Row.

[9] Djankov, Simeon, Rafael La Porta, Florencio Lopez-de-Silanes and Andrei Shleifer (2002): "The Regulation of Entry," The Quarterly Journal of Economics, 117, 1-37.

[10] Farrell, Diana (2004): "The hidden dangers of the informal economy". McKinsey Quarterly, 3, 26-37.

[11] Fortin, Bernard, Nicolas Marceau and Luc Savard (1997): "Taxation, Wage Controls, and the Informal Sector", Journal of Public Economics, 66, 293-312.

[12] Friedman, Eric, Simon Johnson, Daniel Kaufmann, and Pablo Zoido-Lobaton (2000): "Dodging the grabbing hand: the determinants of unofficial activity in 69 countries", Journal of Public Economics, 76, 459-493.

[13] Ghironi, Fabio and Marc J. Melitz (2005): "International Trade and Macroeconomic Dynamics with Heterogeneous Firms," The Quarterly Journal of Economics, 120, 865915.

[14] Hall, Robert E. and Charles I. Jones (1999): "Why do some countries produce so much more output per worker than others?," The Quarterly Journal of Economics, 114, 83-116.

[15] Hopenhayn, Hugo (1992): "Entry, Exit, and Firm Dynamics in Long Run Equilibrium," Econometrica, 60, 1127-1150. 
[16] Loayza, Norman V. (1996): "The economics of the informal sector: a simple model and some empirical evidence from Latin America," Carnegie-Rochester Conference Series on Public Policy, 45, 129-162.

[17] Lucas, Robert E., Jr. (1978): "On the Size Distribution of Business Firms", Bell Journal of Economics, 9, 508-523.

[18] Melitz, Marc J. (2003): "The Impact of Trade on Intra-industry Reallocations and Aggregate Industry Productivity," Econometrica, 71, 1695-1725.

[19] Niepelt, Dirk (2005): "Timing Tax Evasion," Journal of Public Economics, 89, 1611-1637.

[20] OECD (2003): "Revenue Statistics 1965-2002," Revenue Statistics, 4, 1-319.

[21] OECD (2004): "Tax Administration in OECD Countries: Comparative Information Series", mimeo.

[22] Paula, Aureo de and Jose A. Scheinkman (2006): "The Informal Sector", mimeo, Princeton University and UPenn.

[23] Polinsky, A. Mitchell and Steven Shavell (2000): "The Economic Theory of Public Enforcement of Law", Journal of Economic Literature, 38, 45-76.

[24] Rausch, James E. (1991): "Modelling the Informal Sector Formally", Journal of Development Economics, 35, 33-47.

[25] Sarte, Pierre-Daniel G. (2000): "Informality and Rent-Seeking Bureaucracies in a Model of Long-Run Growth," Journal of Monetary Economics, 46, 173-197.

[26] Schneider, Friedrich (2006): "Shadow Economies and Corruption all over the World: What do we really know?," mimeo. 
[27] Schneider, Friedrich and Dominik H. Enste (2000): "Shadow Economies: Size, Causes and Consequences," Journal of Economic Literature, 38, 77-114.

[28] Tybout, James R. (2000): "Manufacturing Firms in Developing Countries: How Well Do They Do, and Why?," Journal of Economic Literature, 38, 11-44.

[29] World Bank (2006): "World Development Indicators," available at http://devdata.worldbank.org/dataonline/ 